Neurodevelopmental indices and the development of psychotic symptoms in subjects at high risk

\title{
of schizophrenia
}

\author{
STEPHEN M. LAWRIE, MAJELLA BYRNE, PATRICK MILLER, \\ ANN HODGES, ROBERT A. CLAFFERTY, DAVID G. CUNNINGHAM OWENS \\ and EVE C. JOHNSTONE
}

\begin{abstract}
Background Neurological 'soft signs' and minor physical anomalies (MPAs) are reported to be more frequent in patients with schizophrenia than in controls.
\end{abstract}

\begin{abstract}
Aims To determine whether these disturbances are genetically mediated, and whether they are central to the genesis of symptoms or epiphenomena.
\end{abstract}

Method We obtained ratings in 152 individuals who were antipsychotic drugfree and at high risk, some of whom had experienced psychotic symptoms, as well as 30 first-episode patients and 35 healthy subjects.

\section{Results MPAs and Neurological \\ Evaluation Scale (NES) 'sensory integration abnormalities' were more frequent in high-risk subjects than in healthy controls, but there were no reliable differences between high-risk subjects with and without psychotic symptoms. MPAs were most frequent in high-risk subjects with least genetic liability and NES scores showed no genetic associations.}

\section{Conclusions The lack of associations with psychotic symptoms and genetic liability to schizophrenia suggests that soft signs and physical anomalies are non- specific markers of developmental deviance that are not mediated by the gene(s) for schizophrenia.}

\section{Declaration of interest None.}

Funding from the Medical Research Council of Great Britain.
Neurological 'soft signs' (NSS) and minor physical anomalies (MPAs) are two putative indices of developmental abnormality which are consistently reported to be more frequent in patients with schizophrenia than in healthy controls (Ismail et $a l, 1998 a, b ;$ McNeil et al, 2000). Subtle neurological dysfunction in patients with psychosis could, however, be secondary to antipsychotic medication or reflect a lack of attention to the tasks. Even if primary, these signs may be attributable to genetic or putative environmental risk factors for schizophrenia. Subtle abnormalities of physical appearance (MPAs) are intrinsically more likely to be primary and genetically mediated, but less likely to be on the causal pathway(s) to psychosis. The relationship between such abnormalities and the genes for schizophrenia is uncertain. It is also unclear whether these abnormalities are directly related to processes that result in the symptoms that mark the advent of psychosis or are simply epiphenomenal indices of a generally disturbed brain development. In this report, we examine the hypothesis that subjects at high risk of developing schizophrenia, some of whom have experienced psychotic symptoms, (a) have increased rates of NSS and MAPs compared with controls; (b) that these rates are higher in high-risk subjects with symptoms than those without; and (c) that they are associated with measures of genetic liability to schizophrenia.

\section{METHOD}

\section{Study groups}

The Edinburgh High-Risk Study is a longitudinal study of subjects at high risk of developing schizophrenia, as they have at least two first- and/or second-degree relatives with schizophrenia. They were initially recruited aged 16-24 years so that they would pass through the age at greatest risk in the subsequent 5-10 years, as previous high-risk studies of subjects recruited as children have had difficulties sustaining contact until a sufficiently high number develop psychotic symptoms. Details of the recruitment process have been described in other papers (Hodges et al, 1999; Johnstone et al, 2000). Briefly, individuals with schizophrenia, with a family history of schizophrenia and with adolescent relatives, were identified from psychiatric hospital case records in many areas of Scotland. Case-note diagnoses of schizophrenia were verified with the Operational Criteria Check-List (OPCRIT; McGuffin $e t$ al, 1991). Potentially suitable high-risk subjects were approached and interviewed with the Present State Examination (PSE; Wing et al, 1974) and Schedule for Affective Disorders and Schizophrenia-Lifetime version (SADS-L; Endicott \& Spitzer, 1978 ) if they agreed to participate. Detailed clinical, neuropsychological and brain imaging assessments were made at intake and have been repeated at 18 -month intervals. Subjects have been encouraged to remain in regular informal contact with the investigators, and their general practitioners have been contacted at regular intervals in an attempt to ensure that any psychotic symptoms are detected. In total, 229 high-risk individuals have been identified and approached, of whom 162 have thus far provided some data. Some of these subjects have experienced psychotic symptoms as elicited with the PSE (Johnstone et al, 2000).

Two control groups have also been recruited (Hodges et al, 1999; Johnstone et al, 2000). A group of 37 age-matched patients experiencing their first episode of schizophrenia have been identified from admissions to the Royal Edinburgh Hospital and associated psychiatric hospitals in Lothian region, Scotland. These subjects have no known family history of schizophrenia in their first- or second-degree relatives. Their case notes have also been reviewed with OPCRIT and the patients have also been examined with the PSE and SADS-L. A group of 36 healthy controls, also without any family history of psychosis, have been recruited from the same areas of the country as the high-risk subjects.

\section{Rating scales}

We obtained ratings on the Neurological Evaluation Scale (NES; Buchanan \& Heinrichs, 1989) and the Waldrop Scale 
(Waldrop \& Halverson, 1971) in 152 highrisk individuals, 30 first-episode patients and 35 healthy controls. Ratings were completed as one of the initial clinical assessments by A.H., R.A.C. and S.M.L. The Waldrop Scale consists of 18 items, in six categories, which are assessed with reference to descriptive anchors and scored (generally 0-2) with a system that is weighted according to abnormalities found in patients with schizophrenia. Two items (head circumference and the binocular distance) are measured with a tape and then assigned to categories by reference to the control mean (as 1.0 or 1.5 standard deviations greater than the control mean). Individual item and total scores are generally calculated. The NES was designed to standardise the neurological assessment of patients with schizophrenia and consists of 26 discrete items, of which 14 are tested and scored for the right and left sides of the body. The instrument includes representative items from three main functional areas of interest - sensory integration, motor coordination and sequencing of complex motor acts - as well as assessment of cerebral dominance, frontal release signs and eye movements. The items are presented in a fixed order and scored on a three-point scale (0, no abnormality; 1 , mild but definite impairment; 2, marked impairment) apart from 'suck' and 'snout' reflexes which are scored 0 or 2 . Descriptive anchors are provided to facilitate standardised judgments. Total scores are calculated for each of the three domains above, the remaining tests and overall. In this study, we did not measure cerebral dominance with the NES or include this item in these totals ('other test' and overall totals), as this was assessed separately in the Edinburgh High-Risk Study.

\section{Genetic liability}

The genetic liability of high-risk individuals to psychosis was measured in two ways. The categorical method simply assigned high-risk individuals to groups of those with only second-degree relatives affected, those with one first- and other seconddegree relatives, and those with two or more first-degree relatives with schizophrenia. A continuous measure was also developed for the Edinburgh High-Risk Study by Pak Sham, Reader in Statistical Genetics at the Institute of Psychiatry. A detailed account of the rationale and calculation of the measure is given in Lawrie et al (2001).
Briefly, we assumed a multifactorial polygenic model of schizophrenia, with a heritability (squared) of 0.7 , to generate a continuous but bimodal measure of genetic loading for each individual based on the expected liabilities of all family members.

\section{Statistical analyses}

Between-group comparisons of the mean ranks of total scores were made with Kruskal-Wallis analysis of variance (ANOVA) and post hoc Mann-Whitney $U$-tests. For the within high-risk by symptoms analysis, high-risk individuals were dichotomised into those with any psychotic symptoms elicited on the PSE versus those with only neurotic symptoms or no symptoms at all - see Johnstone et al (2000) for further details - and total scores compared with the Mann-Whitney $U$-test. The analyses of genetic liability were conducted by comparing mean ranks with the Kruskal-Wallis ANOVA and post hoc Mann-Whitney $U$-tests (for the categorical measure) and by calculating Spearman rank correlation coefficients (for the continuous measure). Finally, we conducted exploratory analyses for each individual test item with $\chi^{2}$ tests and Kruskal-Wallis ANOVA as appropriate.

\section{RESULTS}

One hundred and fifty-two high-risk subjects ( $49 \%$ male), 30 patients with firstepisode schizophrenia (67\% male) and 35 healthy controls ( $49 \%$ male) provided data. All three groups had a mean age of 21 years. Current and past alcohol and illicit drug usage levels were no different across groups (Johnstone et al, 2000). Firstepisode patients were all on antipsychotic medication, but none of the high-risk subjects was. Forty-six of the high-risk individuals (44\% male) had experienced psychotic symptoms and 106 had not. Fifty-two of the high-risk subjects had only second-degree affected relatives, 82 had both first- and second-degree relatives with schizophrenia, and 18 had two or more first-degree relatives with the disorder.

The Waldrop Scale total scores (see Table 1) differed across the three subject groups (Kruskal-Wallis $\chi^{2}=6.1, P=0.047$ ), with controls scoring lower than high-risk subjects and those with schizophrenia. The mean ranks did not differ between high-risk subjects with and without psychotic symptoms $(P=0.5)$. The categorical genetic measure was associated with total scores (Kruskal-Wallis $=5.9, P=0.05$ ), but the scores were highest in the second-degree relatives group and the only statistically significant difference between categories was between them and the group with both first- and second-degree affected relatives. There was no significant Spearman rank correlation between the total scores and the continuous measure of genetic liability $(r=-0.005, P=0.9)$.

Exploratory analyses were conducted on individual items of the Waldrop Scale (see Table 2). Patients with schizophrenia had higher rates of a large head circumference than high-risk subjects and healthy controls $(P=0.009$ overall), although all cases with heads more than 1.5 standard deviations larger than the control mean were male ( $P=0.05$ within men). Subjects with schizophrenia had higher rates of hypertelorism than high-risk subjects, who had higher rates than healthy controls $(P=0.01)$. High-risk individuals also showed a tendency to more malformed ears $(P=0.08)$. There were no statistically significant differences between high-risk subjects with and those without psychotic symptoms. Within the high-risk group, the family history categories showed no association with head circumference or hypertelorism categories; although there was a tendency to an association with malformed ears $(P=0.09)$, these were again most frequent in those with only second-degree relatives. Using the continuous measure of genetic liability, Kruskal-Wallis ANOVA found no association with head circumference or malformed ears categories; although there was an overall association with hypertelorism categories $(P=0.046)$, the median genetic liability was highest in those with hypertelorism of 1-1.5 standard deviations above the control mean, then those with none, and then those with most.

Neurological Evaluation Scale results on the right and left sides were collapsed into one bilateral measure for each test as these results were highly correlated. Patients with schizophrenia had higher overall rates of mild neurological abnormalities than high-risk individuals and healthy controls (Kruskal-Wallis $\chi^{2}=11.5$, $P=0.003$ ) (see Table 1). The same pattern was also evident on 'other tests' $\left(\chi^{2}=10.3\right.$, $P=0.006)$, but all three groups differed on the total scores for tests of sensory integration $\left(\chi^{2}=13.1, P=0.001\right)$. None of these total scores differed between high-risk subjects with and those without psychotic 
Table I Medians (interquartile ranges) for the rating scale totals

\begin{tabular}{|c|c|c|c|c|}
\hline & $\begin{array}{l}\text { Control subjects } \\
\text { (Con) }\end{array}$ & $\begin{array}{l}\text { Subjects at high risk of schizophrenia } \\
\qquad(\mathrm{HR})\end{array}$ & $\begin{array}{l}\text { Subjects with schizophrenia } \\
\text { (Sch) }\end{array}$ & $\begin{array}{c}P \text { value } \\
\text { Kruskal-Wallis ANOVA }\end{array}$ \\
\hline Waldrop total scores & $2(I-3)$ & $3(2-4)$ & $3(2-5)$ & 0.047 (Con < HR, Sch) ${ }^{\prime}$ \\
\hline NES sensory integration & $0(0-0)$ & $0(0-1)$ & I (0-2) & 0.00 I Con $<\mathrm{HR}<\mathrm{Sch})^{\prime}$ \\
\hline NES motor coordination & $0(0-1)$ & $0(0-1)$ & $0(0-2)$ & 0.6 \\
\hline NES complex motor acts & $0(0-2)$ & $0(0-2)$ & $0(0-3)$ & 0.4 \\
\hline NES other tests & $2(0-3)$ & $2(I-3)$ & $2(2-4)$ & 0.006 (Con, HR < Sch) ${ }^{\prime}$ \\
\hline Total NES scores & $3(2-5.25)$ & $3(2-5)$ & $5(4-9)$ & 0.003 (Con, $\mathrm{HR}<\mathrm{Sch})^{\prime}$ \\
\hline
\end{tabular}

I. Post hoc Mann-Whitney $U$-test $P<0.05$.

NES, Neurological Evaluation Scale (Buchanan \& Heinrichs, 1989); Waldrop Scale (Waldrop \& Halverson, 197I).

symptoms. There were also no differences between the median domain scores in the three family history categories and the Spearman rank correlations between the NES domain scores and the continuous measure of genetic liability were uniformly low and non-significant.

The results on the individual tests of the NES are shown in Table 3. There were statistically significant between-group differences on the individual tests of audio-visual integration $(P<0.001)$, rapid alternating movements $(P=0.004)$ and the glabellar reflex $(P=0.001)$ on exploratory analysis, all of which abnormalities were more common in those with schizophrenia than in the other groups. The only difference between high-risk subjects with and those without symptoms was on the glabellar reflex $(P=0.01)$. Neither of the genetic measures showed statistically significant associations with any of the individual NES tests.

\section{DISCUSSION}

\section{Main results}

Our findings support the hypothesis that rates of MPAs differ between high-risk subjects and controls, but these did not differ between subjects at high-risk and those with schizophrenia or by symptoms within the high-risk group. The exploratory findings of large heads in males with schizophrenia and hypertelorism in the patients and high-risk subjects must be interpreted cautiously. Our principal genetic analysis, and two post hoc analyses, found MPAs were, if anything, most common in those with the least genetic liability. These results suggest that MPAs, perhaps particularly of the skull, are trait markers for schizophrenia; but that they are not mediated by the gene(s) for schizophrenia and are not directly related to the development of (positive) psychotic symptoms.

Our NES results showed significant between-group differences in total scores, two domains and three individual tests; although only the sensory integration domain total scores differed between highrisk and control subjects. Only one of 25 comparisons was different between highrisk subjects with and those without psychotic symptoms and no genetic associations were evident. We therefore interpret these findings as evidence that sensory integration abnormalities are non-specific markers of neurodevelopmental abnormality, which cannot be attributed to antipsychotic medication. In general, however, neurological 'soft signs' could be a consequence of schizophrenia or its treatment.

\section{Strengths and limitations of this report}

Studies of individuals at high risk of developing schizophrenia have the potential to tease out genetic effects in the aetiology of schizophrenia. In our high-risk study, this has been enhanced by the development and use of a measure of genetic liability, and this has been particularly illuminating in respect of neuropsychological (Byrne et al, 1999) and structural variables (Lawrie et al, 2001). Large high-risk studies which follow-up sufficient numbers of those who become ill also have the ability to distinguish the causes and consequences of psychosis, in particular the associations of symptoms and the effects of antipsychotic medication. We divided our high-risk subjects by the presence or absence of positive psychotic symptoms, mainly sensory distortions and partial delusions, some of which were transient (Johnstone et $a l, 2000)$ and these results must therefore be regarded as preliminary, particularly as high-risk subjects who develop symptoms at a relatively early age may differ from those who develop them later. The fact that all the high-risk subjects were unmedicated at the time of assessment and indeed had never received antipsychotic medication is, however, a substantial advantage in the interpretation of our results. The very small number of our subjects who have thus far developed psychotic illness means that statistical analysis of the predictors of psychosis would be premature. It would, of course, also be interesting to examine the rates of neurological abnormalities after the onset of psychosis, ideally before and after medication has been prescribed.

The main limitation of the present study is that the raters did not conduct reliability analyses, as we did not wish to risk non-participation in other parts of the study by asking subjects to comply with multiple examinations. The ratings were not blind to group membership but were generally blind to symptom status in the high-risk group as different raters did either all the interviews or all the other clinical assessments on particular days. Any lack of blinding would generally tend to overestimate significant differences whereas any reliability problems may have introduced measurement 'noise' that could have obscured some associations. Clearly, however, the former potential problem did not generate many possible false positive differences between high-risk subjects with and without psychotic symptoms and the latter potential problem did not obscure all the possible differences between the three groups of subjects. Indeed, we have subsequently analysed the distance between the eyes in all subjects on their magnetic resonance imaging brain scans, with a 
Table 2 Frequencies and percentages with minor physical anomalies

\begin{tabular}{|c|c|c|c|c|c|c|c|}
\hline \multirow[b]{2}{*}{ Fine electric hair } & \multicolumn{2}{|c|}{ Control subjects } & Healthy subjects at high risk & \multicolumn{2}{|c|}{ Symptomatic subjects at high risk } & \multicolumn{2}{|c|}{ Subjects with schizophrenia } \\
\hline & & 0 & $2 \quad(1.9 \%)$ & & 0 & & 0 \\
\hline Two or more hair whorls & & 0 & I $\quad(0.9 \%)$ & & 0 & & 0 \\
\hline \multicolumn{8}{|l|}{ Large head circumference } \\
\hline I-I.5 standard deviations & 6 & $(17.1 \%)$ & 13 (12.3\%) & 4 & $(8.9 \%)$ & & $(10.3 \%)$ \\
\hline$>1.5$ standard deviations & 1 & $(2.9 \%)$ & $4 \quad(3.8 \%)$ & 2 & $(4.4 \%)$ & 6 & (20.7\%) \\
\hline \multicolumn{8}{|l|}{ Epicanthus } \\
\hline Part cover & 5 & $(14.3 \%)$ & $8 \quad(7.5 \%)$ & 4 & $(8.9 \%)$ & & 0 \\
\hline Deep cover & & 0 & 0 & I & $(2.2 \%)$ & & 0 \\
\hline \multicolumn{8}{|l|}{ Hypertelorism } \\
\hline I-I.5 standard deviations & 1 & $(2.9 \%)$ & $7 \quad(6.6 \%)$ & 3 & $(6.7 \%)$ & 2 & (6.9\%) \\
\hline$>1.5$ standard deviations & 2 & $(5.7 \%)$ & 32 (30.2\%) & 15 & (33.3\%) & 16 & (55.2\%) \\
\hline \multicolumn{8}{|l|}{ Low-seated ears } \\
\hline $0-0.5 \mathrm{~cm}$ & 1 & $(2.9 \%)$ & $5 \quad(4.7 \%)$ & 1 & $(2.2 \%)$ & 1 & $(3.4 \%)$ \\
\hline$>0.5 \mathrm{~cm}$ & & 0 & $9 \quad(8.5 \%)$ & 3 & $(6.7 \%)$ & 1 & $(3.4 \%)$ \\
\hline \multicolumn{8}{|l|}{ Adherent ear lobes } \\
\hline Backward & II & (31.4\%) & 28 (26.4\%) & 12 & $(26.7 \%)$ & 4 & $(13.8 \%)$ \\
\hline Upward & 2 & $(5.7 \%)$ & $7 \quad(6.6 \%)$ & 3 & $(6.7 \%)$ & 3 & $(10.3 \%)$ \\
\hline Malformed ears & & 0 & $10 \quad(9.4 \%)$ & 5 & (II.I\%) & 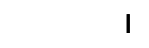 & (3.4\%) \\
\hline Asymmetrical ears & 2 & $(5.7 \%)$ & $7 \quad(6.6 \%)$ & 3 & $(6.7 \%)$ & 1 & $(3.4 \%)$ \\
\hline Soft pliable ears & & (100.0\%) & $106(100.0 \%)$ & & (100.0\%) & & $(100.0 \%)$ \\
\hline \multicolumn{8}{|l|}{ Palate } \\
\hline Narrow top & 16 & (45.7\%) & 34 (32.1\%) & 16 & (35.6\%) & 7 & (24.1\%) \\
\hline Steepled & 3 & $(8.6 \%)$ & $9 \quad(8.5 \%)$ & 2 & $(4.4 \%)$ & 5 & (17.2\%) \\
\hline Furrowed tongue & 1 & $(2.9 \%)$ & II (I0.4\%) & 4 & $(8.9 \%)$ & 2 & $(6.9 \%)$ \\
\hline Smooth-rough spots on tongue & & 0 & I $(0.9 \%)$ & & 0 & I & (3.4\%) \\
\hline \multicolumn{8}{|l|}{ Curved fifth finger } \\
\hline Slightly & 10 & $(28.6 \%)$ & 27 (25.5\%) & 10 & (22.2\%) & 5 & (17.2\%) \\
\hline Markedly & 1 & $(2.9 \%)$ & $4 \quad(3.8 \%)$ & I & $(2.2 \%)$ & & 0 \\
\hline Transverse palm crease & 1 & $(2.9 \%)$ & $10 \quad(9.4 \%)$ & 5 & (II.1\%) & I & $(3.4 \%)$ \\
\hline \multicolumn{8}{|l|}{ Relative toe lengths } \\
\hline Third $=$ second & 2 & $(5.7 \%)$ & $3 \quad(2.8 \%)$ & 2 & $(4.4 \%)$ & 4 & (13.8\%) \\
\hline Third $>$ second & I & $(2.9 \%)$ & I $(0.9 \%)$ & I & $(2.2 \%)$ & & 0 \\
\hline Partial syndactylia & & 0 & $8 \quad(7.5 \%)$ & 3 & $(6.7 \%)$ & 2 & $(6.9 \%)$ \\
\hline Big gap between first two toes & 6 & (17.1\%) & 30 (28.3\%) & 15 & (33.3\%) & 8 & $(27.6 \%)$ \\
\hline
\end{tabular}

completely blind and reliable technique, which confirms the overall differences (although the high-risk group no longer differed from the schizophrenia group) and the lack of differences within the high-risk group by symptoms or genetic liability (Boyes et al, 2001).

\section{Replications and refutations}

The overall differences we report on the Waldrop Scale are in keeping with the original results of Waldrop \& Halverson (1971) and most other previous investigations (McNeil et al, 2000). There is, however, only limited support for our exploratory individual item findings. Waldrop \& Halverson (1971) reported that large head circumference and hypertelorism were found in patients with schizophrenia more frequently than in controls, but Green et al (1989) reported abnormalities of head circumference only in female patients, and Lane et al (1997) found a widened skull base but a reduced binocular diameter in patients. Others have reported an enlarged head circumference in schizophrenia, but a meta-analysis of 10 studies published by 1995 found only a non-significant tendency to larger extracranial size in schizophrenia (Ward et al, 1996).
The lack of positive associations between the Waldrop Scale and psychotic symptoms or genetic liability are also consistent with the existing literature. We are not aware of any studies that have linked Waldrop abnormalities to positive symptoms, but there are at least two that do not find such an association (Lohr \& Flynn, 1993; McGrath et al, 1995). There is, however, at least one study linking MPAs and negative symptoms in male patients (O'Callaghan et al, 1995), which we did not specifically consider in this study. The fact that we found MPAs in high-risk individuals, from multiply affected families, suggests they could be 
genetically mediated but the few specific associations we found suggest that even if genetic, they are not attributable to the genes for schizophrenia. Indeed, most other investigators have been unable to find genetic associations of MPAs (Heinrichs \& Buchanan, 1988; Green et al, 1994; Griffiths et al, 1998). Ismail et al (1998a) recently reported increased rates of MPAs in the siblings of patients with schizophrenia, but the precise anomalies differed from those in the patients. The only exception was that both groups tended to have ear abnormalities. We found tendencies to more malformed ears in high-risk subjects than the other groups, but no associations with increasing genetic liability to schizophrenia, on exploratory analyses.

Several investigators have reported an increased rate of 'soft signs' in patients with schizophrenia (see reviews by Heinrichs \& Buchanan (1988) and Ismail et al (1998b)), but the wide variety of scales used and a general tendency to report total scores rather than presenting individual test data limits the opportunities to compare specific results. It is notable that there are several reports of associations between soft signs and psychotic symptoms, especially negative symptoms and 'thought disorder' (Heinrichs \& Buchanan, 1988; King et al, 1991; Arango et al, 2000). The only difference we found between high-risk subjects with and without (positive) psychotic symptoms was on the glabellar reflex test and this is likely to be a chance finding. Very few of our subjects had negative symptoms or thought disorder, and these could of course adversely affect test performance because of a lack of comprehension of sometimes quite involved instructions and/or a lack of motivation or attentional problems. It is also generally difficult to distinguish primary negative symptoms and those that are secondary to antipsychotic medication. Our results do not resolve these issues, but the findings that sensory integration abnormalities were more evident in (unmedicated) high-risk than in control subjects does at least suggest that 'soft signs' in schizophrenia are not entirely attributable to these potential confounders.

The relationship between a family history of schizophrenia and soft signs is also complex. Most studies of patients with schizophrenia have not found such an association (Kolakowska et al, 1985; Heinrichs \& Buchanan, 1988; King et al, 1991), but the problems with reliably ascertaining family history mean that
Table 3 Frequencies and percentages' with neurological 'soft signs'

\begin{tabular}{|c|c|c|c|c|}
\hline & $\begin{array}{l}\text { Control } \\
\text { subjects }\end{array}$ & $\begin{array}{c}\text { Healthy subjects } \\
\text { at high risk }\end{array}$ & $\begin{array}{c}\text { Symptomatic } \\
\text { subjects at high risk }\end{array}$ & $\begin{array}{l}\text { Subjects wit } \\
\text { schizophren }\end{array}$ \\
\hline \multicolumn{5}{|l|}{ Sensory integration } \\
\hline \multicolumn{5}{|l|}{ Audio visual } \\
\hline I error & 0 & $3(2.8 \%)$ & 2 (4.4\%) & $5(16.7 \%)$ \\
\hline$>I$ error & 0 & 0 & 0 & $2(6.7 \%)$ \\
\hline \multicolumn{5}{|l|}{ Stereognosis } \\
\hline I error & 0 & I (0.9\%) & 0 & $2(6.7 \%)$ \\
\hline$>I$ error & 0 & 2 (1.8\%) & 0 & $2(6.7 \%)$ \\
\hline \multicolumn{5}{|l|}{ Graphaesthesia } \\
\hline I error & 0 & 0 & I (2.2\%) & $2(6.7 \%)$ \\
\hline$>$ I error & I (2.9\%) & $12(11.3 \%)$ & $7(15.2 \%)$ & 4 (13.3\%) \\
\hline \multicolumn{5}{|l|}{ Extinction } \\
\hline I error & 0 & I (0.9\%) & 0 & $2(6.9 \%)$ \\
\hline$>1$ error & 0 & 0 & I (2.2\%) & 0 \\
\hline \multicolumn{5}{|l|}{ Right/left confusion } \\
\hline I error & 13 (37.1\%) & $29(27.4 \%)$ & $10(21.7 \%)$ & $10(33.3 \%)$ \\
\hline 2 or more errors & $3(8.6 \%)$ & $17(16.0 \%)$ & $8(17.4 \%)$ & $6(20.0 \%)$ \\
\hline
\end{tabular}

Motor coordination

Rapid alternating movements

$\begin{array}{lccc}\text { Hesitations } & 0 & \text { I } & (0.9 \%) \\ \text { Disruptions } & \text { I }(2.9 \%) & 4 & (3.8 \%) \\ \text { Tandem walk } & & & \\ \text { I or } 2 \text { mis-steps } & 5(14.3 \%) & 8 & (7.5 \%) \\ \geqslant 3 \text { mis-steps } & 0 & \text { I } & (0.9 \%)\end{array}$

I $(2.2 \%)$

$3(10.0 \%)$

$2(4.3 \%)$

$5(16.6 \%)$

$2(4.3 \%)$

I (3.3\%)

$\geqslant 3$ mis-steps

(0.9\%)

I (2.2\%)

I (3.3\%)

Finger-thumb

opposition

2-3 mistakes

I (0.9\%)

3 (6.5\%)

$2(4.3 \%)$

0

Disruption

3 (8.6\%)

3 (2.8\%)

$4(13.3 \%)$

Finger-to-nose test

Mild tremor

I (2.9\%)

4 (3.8\%)

2 (4.3\%)

2 (6.7\%)

Marked tremor

4 (II.4\%)

14 (13.2\%)

2 (4.3\%)

2 (6.7\%)

Complex motor acts

First-ring test

Mild disruption

Major disruption

0

4 (3.8\%)

4 (13.3\%)

2 (4.3\%)

$6(20.0 \%)$

First-edge-palm test

$4(11.4 \%) \quad 23(21.7 \%)$

7 (I5.2\%)

$2(6.7 \%)$

Mild disruption

$6(5.7 \%)$

I $(2.2 \%)$

$9(30.0 \%)$

Ozeretski test

Mild disruption

7 (20.0\%)

$25(23.6 \%)$

$8(17.4 \%)$

4 (13.3\%)

Major disruption

3 (8.6\%)

$8(17.4 \%)$

$8(26.7 \%)$

Rhythm tapping

$\begin{array}{llr}\text { I error } & 4(11.4 \%) & 15(14.2 \%) \\ >\text { I error } & 2(5.7 \%) & 2(1.9 \%)\end{array}$

$5(10.9 \%)$

I (3.3\%)

I (2.2\%)

2 (6.7\%)

\section{Other tests}

Adventitious overflow

$\begin{array}{lcccc}\text { Fingers only } & 3(8.6 \%) & 5(4.7 \%) & 5(10.9 \%) & 2(6.7 \%) \\ \text { Hands and arms } & 0 & 0 & 1(2.2 \%) & 1(0.5 \%)\end{array}$




\begin{tabular}{|c|c|c|c|c|}
\hline & $\begin{array}{l}\text { Control } \\
\text { subjects }\end{array}$ & $\begin{array}{l}\text { Healthy subjects } \\
\text { at high risk }\end{array}$ & $\begin{array}{c}\text { Symptomatic } \\
\text { subjects at high risk }\end{array}$ & $\begin{array}{l}\text { Subjects with } \\
\text { schizophrenia }\end{array}$ \\
\hline \multicolumn{5}{|l|}{ Romberg test } \\
\hline Swaying & I (2.9\%) & $5(4.7 \%)$ & $2(4.3 \%)$ & 0 \\
\hline Unbalanced & 0 & I (0.9\%) & 0 & 0 \\
\hline \multicolumn{5}{|l|}{ Tremor } \\
\hline Mild & $3(8.6 \%)$ & $5(4.7 \%)$ & I (2.2\%) & $3(10.0 \%)$ \\
\hline Marked & 0 & 0 & 0 & $2(6.7 \%)$ \\
\hline \multicolumn{5}{|l|}{ Memory } \\
\hline 3 words & $8(22.9 \%)$ & $21(20.0 \%)$ & 10 (21.7\%) & 7 (23.3\%) \\
\hline$<3$ words & $4(11.4 \%)$ & $22(21.0 \%)$ & $6(13.0 \%)$ & $4(13.3 \%)$ \\
\hline \multicolumn{5}{|l|}{ Mirror movements } \\
\hline Minor & I (2.9\%) & $5(4.7 \%)$ & $4(8.7 \%)$ & I (3.3\%) \\
\hline Consistent & $12(34.3 \%)$ & 49 (46.3\%) & $14(30.4 \%)$ & $6(20.0 \%)$ \\
\hline \multicolumn{5}{|l|}{ Synkinesis } \\
\hline Some & $3(8.6 \%)$ & II (10.4\%) & $3(6.5 \%)$ & I (3.3\%) \\
\hline Much & I (2.9\%) & $5(4.7 \%)$ & $4(8.7 \%)$ & $2(6.7 \%)$ \\
\hline \multicolumn{5}{|l|}{ Convergence } \\
\hline Incomplete & 0 & $2(1.9 \%)$ & 0 & 0 \\
\hline Less than half & $3(8.6 \%)$ & $7(6.6 \%)$ & $3(6.3 \%)$ & $12(24.1 \%)$ \\
\hline \multicolumn{5}{|l|}{ Gaze impersistence } \\
\hline Deviation $>20 s$ & 0 & I (0.9\%) & 0 & 0 \\
\hline Deviation $<20$ s & I (2.9\%) & $5(4.7 \%)$ & $4(8.7 \%)$ & $4(13.4 \%)$ \\
\hline \multicolumn{5}{|l|}{ Glabellar reflex } \\
\hline 4-5 blinks & $4(11.4 \%)$ & 15 (14.2\%) & II (23.9\%) & $4(13.8 \%)$ \\
\hline$\geqslant 6$ blinks & $2(5.7 \%)$ & I (0.9\%) & $4(8.7 \%)$ & 7 (24.1\%) \\
\hline Snout reflex & $2(5.7 \%)$ & $3(2.8 \%)$ & $\mathrm{I}(2.2 \%)$ & I (3.4\%) \\
\hline Suck reflex & I (2.9\%) & $2(1.9 \%)$ & 0 & I (3.4\%) \\
\hline \multicolumn{5}{|l|}{ Grasp reflex } \\
\hline Flexion & 0 & 0 & 0 & 0 \\
\hline \multicolumn{5}{|l|}{ Cerebral dominance } \\
\hline Right hand & 30 (85.7\%) & $92(86.8 \%)$ & $43(93.5 \%)$ & 27 (90.0\%) \\
\hline Left hand & $3(8.6 \%)$ & $10(9.4 \%)$ & 0 & 0 \\
\hline Mixed & $2(5.7 \%)$ & $4(3.8 \%)$ & $3(6.5 \%)$ & $3(10.0 \%)$ \\
\hline
\end{tabular}

I. Count percentages vary owing to rounding and because not all subjects completed all tests.

studies of siblings and high-risk subjects are more reliably informative. Siblings of people with schizophrenia have consistently been shown to have rates of soft signs somewhere between those observed in controls and their affected siblings (Heinrichs \& Buchanan, 1988; Rossi et al, 1990; Ismail et al, 1998b; Chen et al, 2000). Offspring at high risk have also been shown to have higher rates of sensoryperceptual and motor coordination signs (Marcus et al, 1985). None of these studies has been able to separate specific from nonspecific genetic or environmental effects. Our findings are broadly in keeping with these reports, but extend them by showing no association between genetic liability to schizophrenia and neurological soft signs.

\section{Implications}

We conclude that MPAs and at least some neurological 'soft signs' are over-represented in high-risk samples and patients with schizophrenia, but are not associated with the development of positive psychotic symptoms or genetic liability to schizophrenia. Rather, they probably represent subtle developmental abnormalities that are found in a range of brain disorders. This is in keeping with observations that MPAs are frequently observed in several neuropsychiatric conditions (McNeil et al, 2000) and that 'soft signs' are also evident in patients with other psychoses, affective disorders and substance misuse (Woods et al, 1986; Lohr \& Flynn, 1993; McGrath et al, 1995).

This is not to say that studying MPAs and soft signs is uninformative, as they can clearly give pointers to the timing and processes of neurodevelopmental deviance in schizophrenia and other disorders. There is, for example, a close relationship between cerebral and craniofacial development (Diewert et al, 1993). It is possible that these anomalies reflect common underlying factors that are more directly related to the development of schizophrenia. It is even possible that the high-risk subjects in our study may show a more specific relationship between these abnormalities and symptoms as and when a greater number develop frank psychosis, particularly negative symptoms.

Some of our exploratory findings suggest particular avenues for potentially fruitful further study - although these must be viewed cautiously given the large number of statistical tests performed and the lack of strong support for them in the literature. The hypertelorism and head circumference findings suggest that highrisk subjects with these anomalies may be at particular risk of developing schizophrenia, perhaps because they have been exposed to more than one genetic and/or environmental risk factor. Hypertelorism probably reflects abnormal development of the face, which can arise for a number of reasons (Diewert et al, 1993). Alternatively, relatively distinct disease processes may be involved, that is, some patients with schizophrenia have large heads and others have small heads related to different causal processes. For example, a small head at birth suggests a prenatal (second trimester) developmental abnormality; large heads at birth could reflect arrested hydrocephalus, whereas a large head in adulthood could be due to skull overgrowth secondary to early childhood head trauma or the pleiotropic expression of a developmental gene as in fragile- $X$ syndrome. Finally, it is conceivable that families with facial abnormalities and schizophrenia form a distinct subgroup with variants of velo-cardio-facial or similar syndromes.

\section{ACKNOWLEDGEMENTS}

We thank the Medical Research Council of Great Britain for funding; Elizabeth Grant, Jane Morris and 
Suheib Abukmeil for assistance in recruiting subjects and conducting some of the clinical assessments; Norma Brearley for careful preparation of the manuscript; general practitioners and psychiatrists throughout Scotland; and the subjects themselves and their extended families.

\section{REFERENCES}

Arango, C., Kirkpatrick, B. \& Buchanan, R.W. (2000) Neurological signs and the heterogeneity of schizophrenia. American Journal of Psychiatry, 157, 560-565.

Boyes, J., Whalley, H. C., Lawrie, S. M., et al (200I) $\mathrm{MRI}$ assessment of hypertelorism in those at high risk of schizophrenia. Schizophrenia Research, in press.

Buchanan, R.W. \& Heinrichs, D.W. (1989) The Neurological Evaluation Scale (NES): a structured instrument for the assessment of neurological signs in schizophrenia. Psychiatry Research, 27, 335-350.

Bryne, M., Hodges, A., Grant, E., et al (1999)

Neuropsychological assessment of young people at high genetic risk for developing schizophrenia compared with controls: preliminary findings of the Edinburgh High Risk Study (EHRS). Psychological Medicine, 29, ||6|-|173.

Chen, Y. L. R., Chen, Y. H. E. \& Mak, F. L. (2000) Soft neurological signs in schizophrenic patients and their nonpsychotic siblings. Journal of Nervous and Mental Disease, 188, 84-89.

\section{Diewert, V. M., Lozanoff, S. \& Choy, V. (1993)} Computer reconstructions of human embryonic craniofacial morphology showing changes in relations between the face and brain during primary palate formation. Journal of Craniofacial Genetics and Developmental Biology, I3, |93-20|.

Endicott, J. \& Spitzer, R. L. (1978) A diagnostic interview schedule for affective disorders and schizophrenia. Archives of General Psychiatry, 35, 837-844

Green, M. F., Satz, P., Gaier, D. J., et al (1989) Minor physical anomalies in schizophrenia. Schizophrenia Bulletin, 15, 91-99.

_, _ \& Christenson, C. (1994) Minor physical anomalies in schizophrenia patients, bipolar patients, and their siblings. Schizophrenia Bulletin, 20, 433-440.

Griffiths, T. D., Sigmundsson, T., Takei, N., et al (1998) Minor physical anomalies in familial and sporadic schizophrenia: the Maudsley family study. Journal of Neurology, Neurosurgery and Psychiatry, 64, 56-60.

Heinrichs, D.W. \& Buchanan, R.W. (1988) Significance and meaning of neurological signs in schizophrenia. American Journal of Psychiatry, 145, II-18.

Hodges, A., Byrne, M., Grant, E., et al (1999) People at risk of schizophrenia. Sample characteristics of the first 100 cases in the Edinburgh High-Risk Study. British Journal of Psychiatry, 174, 547-553.

Ismail, B., Cantor-Graae, E. \& McNeil, T. F. (1998a)

Minor physical anomalies in schizophrenic patients and their siblings. American Journal of Psychiatry, $\mathbf{1 5 5}$, 1695-1702.

_, _ \& _ (1998b) Neurological abnormalities in schizophrenic patients and their siblings. American Journal of Psychiatry, 155, 84-89.

Johnstone, E. C., Abukmeil, S. S., Byrne, M., et al (2000) Edinburgh High Risk Study - findings after fou years: demographic, attainment and psychopathological issues. Schizophrenia Research, 46, I-15.

\section{CLINICAL IMPLICATIONS}

- Minor physical anomalies (MPAs) and at least some neurological 'soft signs' may be trait markers for schizophrenia.

- 'Soft signs' are not simply attributable to the effects of antipsychotic medication.

- MPAs are non-specific markers of neurodevelopmental deviance.

\section{LIMITATIONS}

- We did not conduct formal assessments of interrater reliability.

These results may not be generalisable to all cases of schizophrenia.

- The associations of individual psychotic symptoms in high-risk subjects may differ from the associations of the constellation of symptoms required for a diagnosis of schizophrenia.

STEPHEN M. LAWRIE, MRCPsych, MAJELLA BYRNE, MA, PATRICK MILLER, PhD, ANN HODGES, MRCPsych, ROBERT A. CLAFFERTY, MRCPsych, DAVID G. CUNNINGHAM OWENS, FRCPsych, EVE C. JOHNSTONE, FRCPsych, Edinburgh University Department of Psychiatry, Edinburgh

Correspondence: Dr Stephen M. Lawrie, Edinburgh University Department of Psychiatry, Royal Edinburgh Hospital, Edinburgh EHI0 5HF, UK. Tel: 0I3I-537-667I ; Fax: 0I3I-447-6680; e-mail: s.lawrie@ed.ac.uk

(First received 3 July 2000, final revision II December 2000, accepted I5 December 2000)

King, D. J., Wilson, A., Cooper, S. J., et al (1991) The clinical correlates of neurological soft signs in chronic schizophrenia. British Journal of Psychiatry, 158, 770-775.

Kolakowska, T., Williams, A. O., Jambor, K., et al (1985) Schizophrenia with good and poor outcome. III: Neurological 'soft' signs, cognitive impairment and their clinical significance. British Journal of Psychiatry, 146 348-357.

Lane, A., Kinsella, A., Murphy, P., et al (1997) The anthropometric assessment of dysmorphic features in schizophrenia as an index of its developmental origins Psychological Medicine, 27, II55-1164.

Lawrie, S. M., Whalley, H. C., Abukmeil, S. S., et al (200I) Brain structure, genetic liability and psychotic symptoms in subjects at high risk of developing schizophrenia. Biological Psychiatry, in press.

Lohr, J. B. \& Flynn, K. (1993) Minor physical anomalies in schizophrenia and mood disorders. Schizophrenia Bulletin, 19, 551-556.

Marcus, J., Hans, S. L., Lewow, E., et al (1985) Neurological findings in high-risk children: childhood assessment and 5-year follow-up. Schizophrenia Bulletin, II, 85-100.

McGrath, J. J., van Os, J., Hoyos, C., et al (1995) Minor physical anomalies in psychoses: associations with clinical and putative aetiological variables. Schizophrenia Research, 18, 9-20.

McGuffin, P., Farmer, A. \& Harvey, I. (1991) A polydiagnostic application of operational criteria in studies of psychotic illness. Development and reliability of the OPCRIT system. Archives of General Psychiatry, 48, 764-770.

McNeil, T. F., Cantor-Graae, E. \& Ismail, B. (2000) Obstetric complications and congenital malformation in schizophrenia. Brain Research Reviews, 3I, 166-178.

O'Callaghan, E., Buckley, P., Madigan, C., et al (1995) The relationship of minor physical anomalies and other putative indices of developmental disturbance in schizophrenia to abnormalities of cerebral structure on magnetic resonance imaging. Biological Psychiatry, 38 516-524.

Rossi, A., De Cataldo, S., Di Michele, V., et al (1990) Neurological soft signs in schizophrenia. British Journal of Psychiatry, 157, 736-739.

Waldrop, M. F. \& Halverson, C. F., Jr (197I) Minor Physical Anomalies and Hyperactive Behavior in Young Children. New York: Brunner/Mazel.

Ward, K. E., Friedman, L., Wise, A., et al (1996) Metaanalysis of brain and cranial size in schizophrenia. Schizophrenia Research, 22, 197-213.

Wing, J. K., Cooper, J. E. \& Sartorius, N. (1974) The Description and Classification of Psychiatric Symptoms. An Instruction Manual for the PSE and Catego Systems. Cambridge: Cambridge University Press.

Woods, B. T., Kinney, D. K. \& Yurgelun-Todd, D. (1986) Neurologic abnormalities in schizophrenic patients and their families. I. Comparison of schizophrenic, bipolar, and substance abuse patients and normal controls. Archives of General Psychiatry, 43 657-663. 